- State of -The-Art

\title{
Palliative Care of Cancer Patient: A Successful Charitable
}

Experience

Nadia Yanni Seif

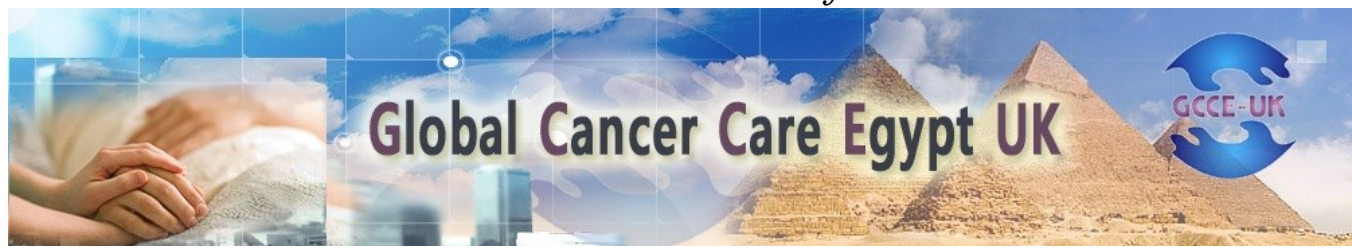

Cancer is worldwide spreading disease; it is generally and roughly estimated as 7.2 to 7.5 million people die from cancer each year. Also, more than $70 \%$ of all cancer deaths occur in developing countries, where resources available for prevention, diagnosis and treatment of cancer are limited or nonexistent. Furthermore, more than $40 \%$ of all cancers can be prevented. Others can be detected early, treated, and cured. Cancer and its treatment can cause symptoms and side effects, including physical, emotional, social, and financial. Therefore, treating these effects with even late-stage cancer, the suffering of patients can be relieved with a good care called palliative care or supportive care.

According to the World Health Organization, 2019 palliative care is described as "an approach that improves the quality of life of patients and their families facing the problems associated with life-threatening illness, through the prevention and relief of suffering by means of early identification and impeccable assessment and treatment of pain and other problems, physical, psychosocial and spiritual."

https://www.who.int/cancer/palliative/definition/en /

Palliative care has been started as a hospice movement in the 19th century, religious orders created hospices that provided care for the sick and dying in London and Ireland. In recent years, Palliative care has become a large movement, affecting much of the population. In the United States, it started as a volunteer-led movement and has developed into a vital part of the health care 
system. Actually, Hospice is a "type" of palliative care provided for those who are at the end of their lives; its goal is to keep the cancer patient as comfortable as possible when treatment is not expected to cure the cancer.

On the other hand, the palliative care is to prevent or treat, as early as possible, the symptoms, side effects of the disease and its treatment, besides any related psychological, social, and spiritual problems. Meanwhile, it is an approach that achieves the patient needs, not just care for disease. However, palliative care is an important part of patient's care that included along with treatments. Researchers showed that palliative care can improve the quality of life of patients, who have a serious or life-threatening disease, such as cancer and help to feel more satisfied with the receive treatment.

Nevertheless, palliative care is called comfort care, supportive care, and symptom management. Patients may receive palliative care in the hospital, an outpatient clinic, long-term care facility, or at home under the physician's direction. Palliative care starts soon after the patient diagnosed as cancer and continues to receive this type of care through treatment and recovery. For example, cancer survivors who have ongoing or new symptoms or side effects after treatment is completed also may receive palliative care.

Palliative care nursing can be provided in a variety of settings, wherever a patient in need resides; in hospitals, nursing homes, assisted living facilities, and private homes. Settings where the older adults convene or where chronic conditions are treated (like critical care units) are some of the most common places where palliative care nurses work. Many end-of-life patients prefer to have in-home palliative care if possible .

Nurses with a wide variety of care backgrounds can become palliative care nurses. Those who have experience with geriatric care and certain terminal diseases like late-stage cancer and heart disease are good candidates for this specialty. Strong communication skills are also needed, as palliative care nurses often coordinate with the patient's family. Lastly, empathy and compassion are 
needed to be successful as a palliative care nurse, as emotions can run high when death is involved.

Palliative care nurses must often strike the balance of alleviating the symptoms and pain of their patient without over-sedating them. Their main concern is to make the patient as comfortable as possible. They also provide important emotional support to the patient and their family, and often educate those involved regarding new ways to manage symptoms, as well as provide and monitor pain management; Help to alleviate physical symptoms (i.e. respiratory difficulties, nausea, etc.); Dispense medications on schedule; Educate patients and families on symptom management .

The Global Cancer Care (GCC-UK) staff from UK; Rotherham and St. Luke's Hospices, Sheffield, and trustees of the GCC; combined their interests, knowledge and experience to work on this shared goal. They were approached to support work on that care project of cancer patient. They were very keen to introduce the principles of palliative care to Egypt to improve the care available to such patients, and their families.

A number of interested members in Charity Centers in Egypt, who are serving patients with long term serious conditions including cancer visited UK (I am one of them ) to get acquainted with the principles of palliative care, as practiced there. Many people have kindly supported Global Cancer Care Egypt (GCCE) both financially and morally since Year 2002. Those are mostly, brothers and sisters from various churches throughout the UK, and individuals who exert tremendous efforts to raise funds for the charity.

Many of those interested doctors, nurses and other healthcare professionals have come from Egypt for training at hospices in the UK, mainly Rotherham Hospice, St. Luke's Hospice, Sheffield, and the Macmillan Palliative Care Unit, Sheffield. Simultaneously visits to Egypt by medical and nursing specialists from the UK have taken place between 2003 and 2014 to provide education and training to healthcare professionals as doctors and nurses, as well as volunteers in Egyptian Hospitals, Universities and Churches. 


\section{Training objectives of Palliative Care for Cancer Patient:}

To provide support for individuals living with advanced cancer, their families, and careers through:

- Promote a high standard of care and support to enhance patients and their families' quality of life.

- Promote attention to all patient's palliative needs; physical, psychological, social, or financial.

- Promote multi-professional team working to ensure full patient' support, care and advice are provided at the day centers and at home.

- Provide support for the professional careers and the volunteers.

- Provide training for the multi-professional teams when required.

- Encourage networking between the International centers, and Conferences to share practice and enhance learning.

- Encourage the establishment of more palliative care centers in areas where there is little or no access to palliative care.

- Provide financial support to the palliative care centers where appropriate.

- Collaborate with other organizations and work towards the establishment of a national association of palliative care in Egypt.
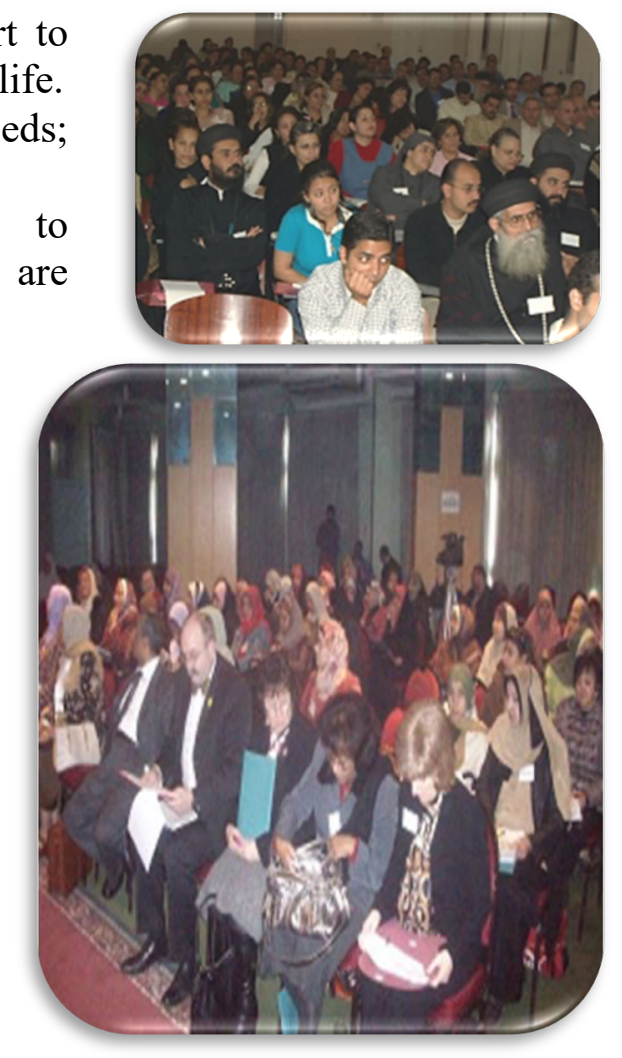

\section{Summary Work Carried out:}

1. Skills orientation \& Training of doctors and nurses in the UK.

2. Palliative medicine and nursing expert's visits to Egypt.

3. Community awareness through Organizing Conferences and workshops /lectures at universities, institutes, churches, and centers in Egypt such as:

Cancer Center Mansoura University; Nursing College, Ain-Shams University; High Institute of Medical Research, Alexandria; Nursing College, Alexandria University, American Hospital, Tanta; Meridian Hotel, Pyramids; and Ayadi-al-Mostakbal Charity, Alexandria. 


\section{Establishing and/or supporting Palliative Care Centers at different governorates:}

5. Printing and distribution of brochures about common types of cancer and symptoms management and preparing a palliative care curriculum in Arabic.

Currently, GCCE-UK provides funding and support to eight Christian palliative care centers including a hospice in Tema, Sohag Governorate and a one near completion at Abo-Talat, west of Alexandria. Each center comprises day care (with transport), community visits, and relative support. Money donated helps to test, provide medicines for symptom medication, and when required hospital beds, as well as the education and training already mentioned. Staff and volunteers in the centers also provide days out and two - three nights' holiday for patients and their families.

\section{Establishing and/or supporting Palliative Care Centers at different Governorates:}

\section{Palliative Care Centers at Different Egyptian Governorates}
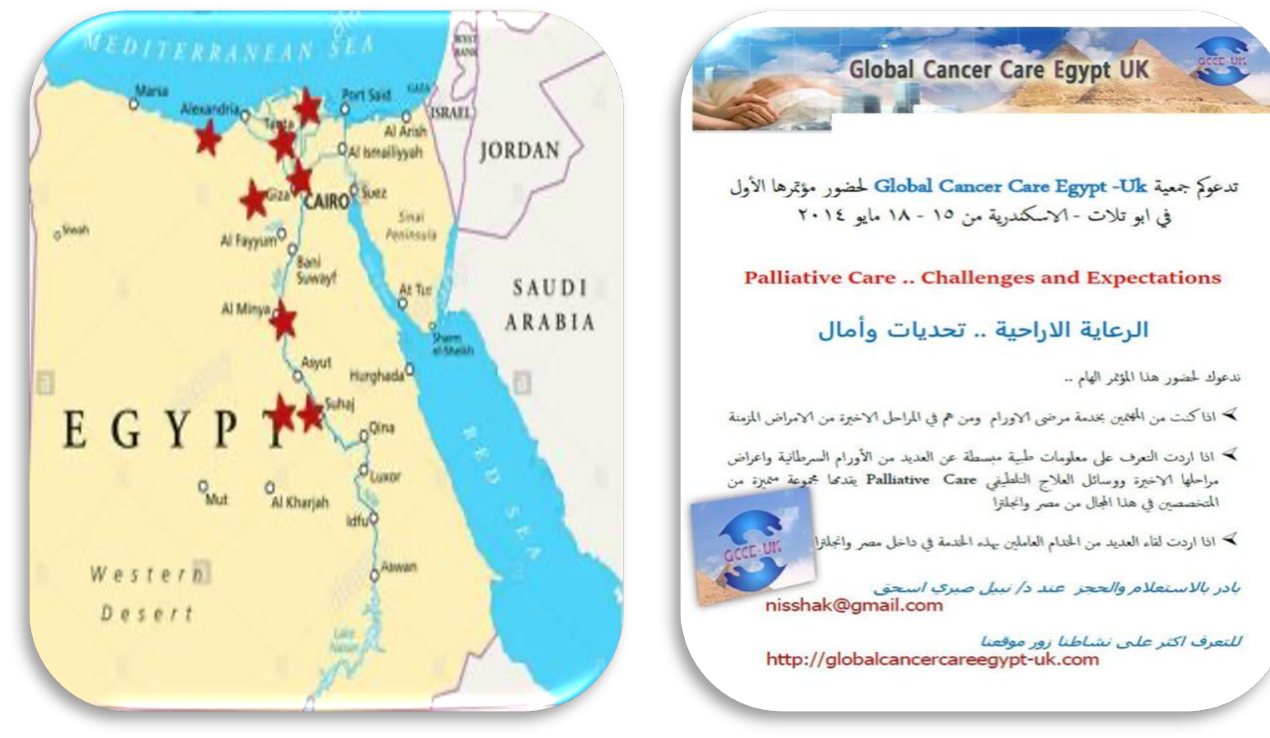
A Conference for Professors and Nurses of the Oncology Department, Faculty of Nursing Alexandria University, Jan. (2008)
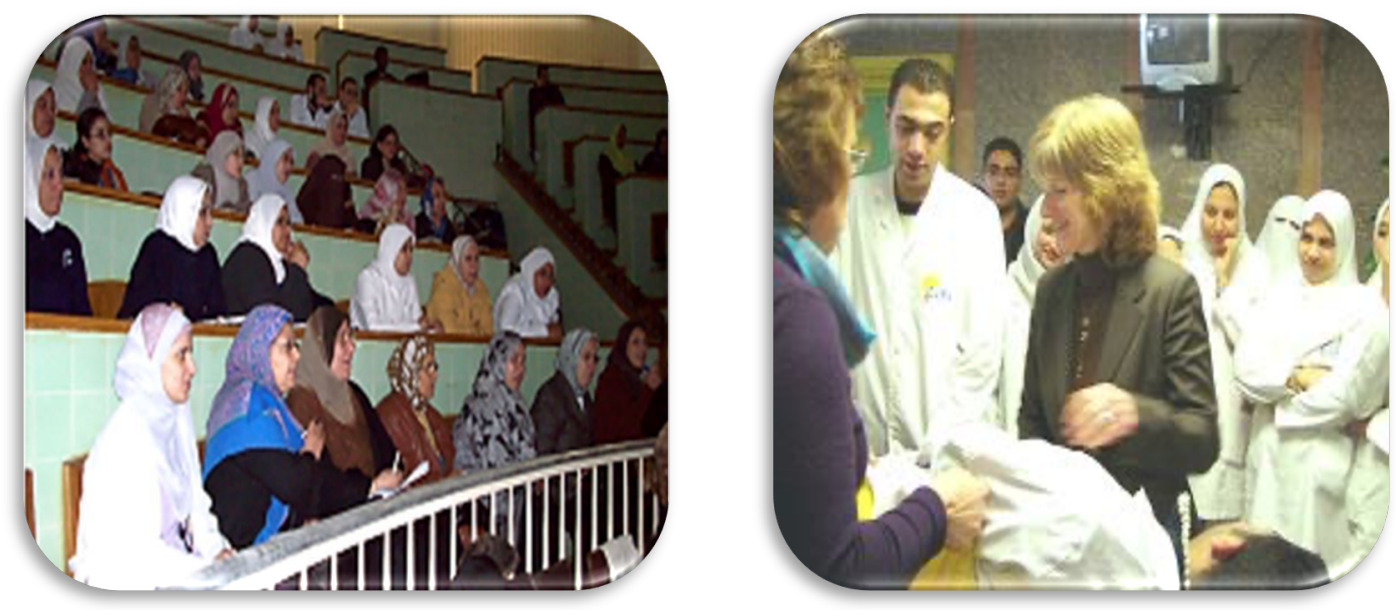

International Conference in Faculty of Nursing- Ain-Shams University

(Jan 2008)
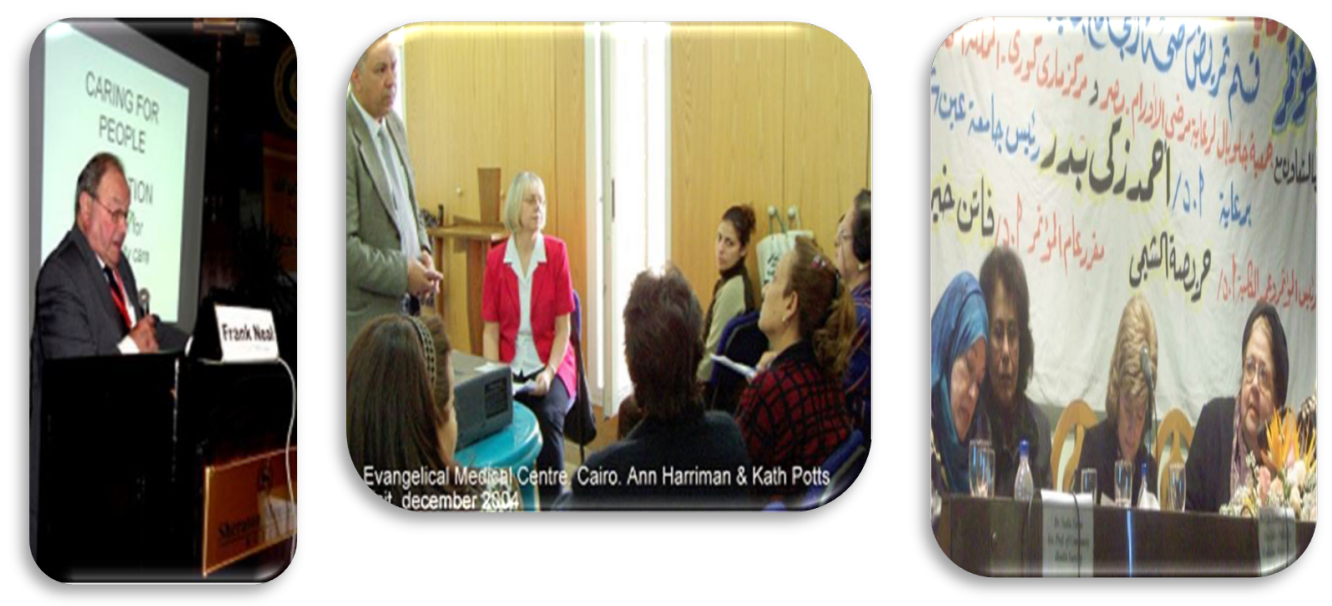

Prof. Nadia Yanni Seif Community Health Nursing, M TI University 


\section{الملخص العربي}

\section{الرعايه التسكينيه \التططيفيه لمرضي السرطان : خبره تطوعيه ناجحه}

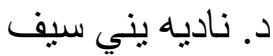

الواقع الأليم يثبت أن المرض السرطاني يتم تشخيصه في مراحل متقدمة في كثير من الحالات،

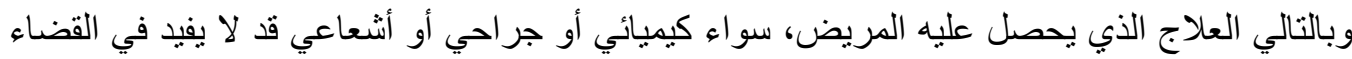

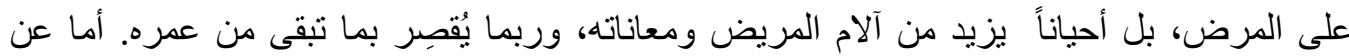

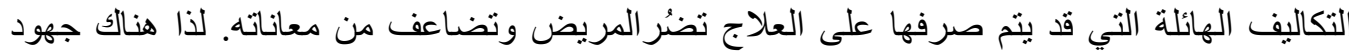

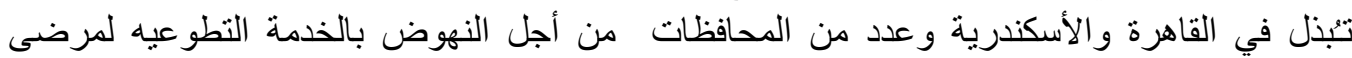

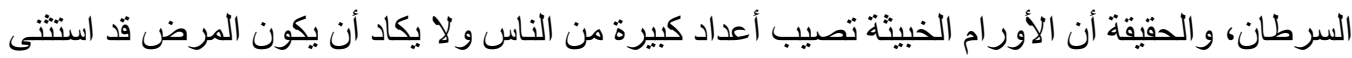
عائلة منه. وقد رأيت الفارق الهائل في العناية بمريض السرطان، في مر احله المتقدمة، بين مستشفيات

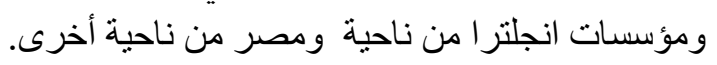

في المملكة المتحدة نجد صورة متشابهة فتقريباً كل عائلة اختبرت السرطان حين يصبب أحد

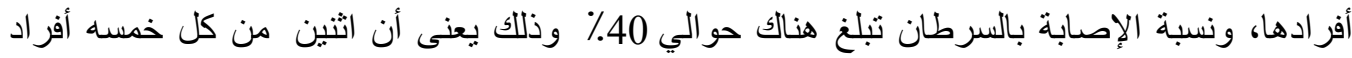

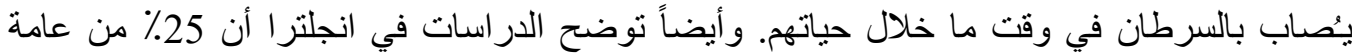
الثعب يموت بالسرطان بمعدل و احد من كل أربعة.

من هنا كان الاهتمام الكبير بالقيام بدراسات وبرامج لتحسين الوضع بالتشخيص و العلاج المبكر

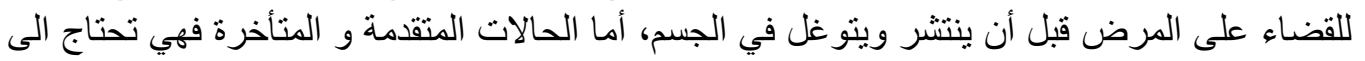

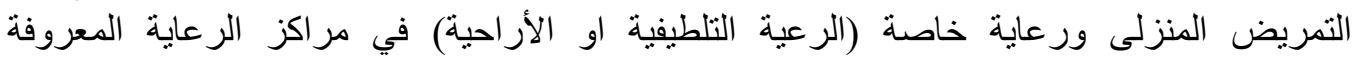
بـالهو سبيسات.

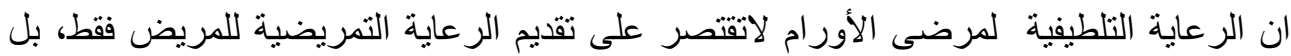

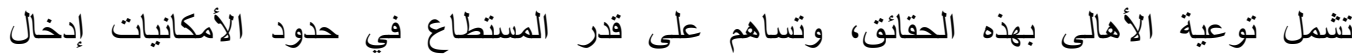

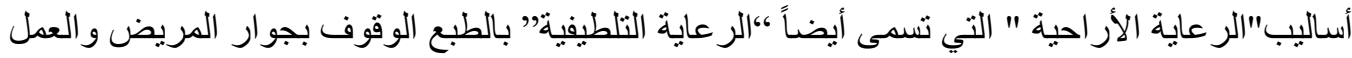

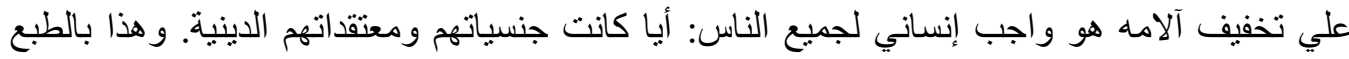

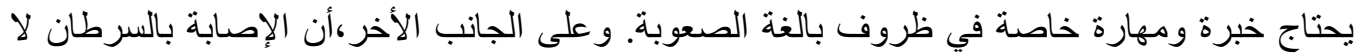

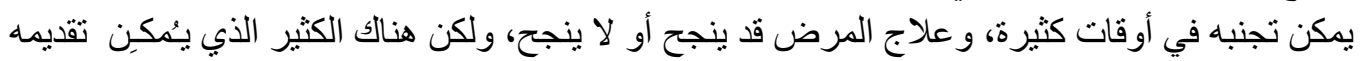

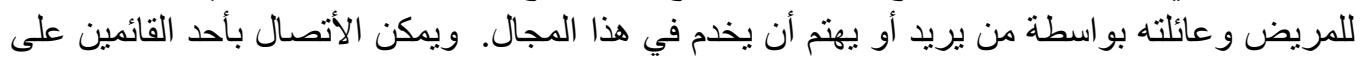
هذه الخدمة في مصر أو بأحد من مسئولي.

“جلوبال لرعاية مرضى الأورام مصر- المملكة المتحدة" 